\title{
Effect of Total Amount of Metformin HCl on the Characteristics of Metformin-Ca Alginate Microspheres
}

Dewi Melani Hariyadi*, Noorma Rosita, Tiara Jeni Rosadi

Department of Pharmaceutics, Faculty of Pharmacy, Universitas Airlangga, Surabaya

*Corresponding Author: dewi-m-h@ff.unair.ac.id

\begin{abstract}
Introduction: Metformin hydrochloride (metformin $\mathrm{HCl}$ ) is an antidiabetic drug that is specifically used for type 2 diabetes mellitus (DM) and belongs to the biguanide antidiabetic drugs. Objective: The aim of this research was to determine the effect of total amount of metformin $\mathrm{HCl}$ on the characteristics of metformin $\mathrm{HCl}-\mathrm{Ca}$ alginate microspheres using aerosolization technique. Methods: The total amount of metformin were $0.5 \mathrm{~g}(F 1)$; $1 \mathrm{~g}(\mathrm{~F} 2) ; 1.5 \mathrm{~g}(\mathrm{~F} 3)$ and $2 \mathrm{~g}$ (F4). Drug was encapsulated into alginate and was crosslinked using $\mathrm{CaCl}_{2}$. Results: The results showed that drug loadings were 5.09\%; 9.61\%; 13.11\%; and 15.09\% respectively, while the entrapment efficiencies were $48.35 \%$; $41.99 \%$; $38.67 \%$; and $30.53 \%$. The yields were $80.92 \%$; $74.12 \%$; $68.27 \%$; and $59.11 \%$ respectively. Based on the statistical analysis, it was found that there were significant differences between formulas. Particles of formulas decreased as the amount of drug increased. The resulting sizes were $1.82 \mu \mathrm{m}$ (F1); $1.96 \mu \mathrm{m}$ (F2); $2.1 \mu \mathrm{m}$ (F3); and $2.97 \mu \mathrm{m}$ (F4). Conclusion: It can be concluded that amount of drug significantly affected the characteristics of metformin-alginate microspheres.
\end{abstract}

Keywords: metformin $\mathrm{HCl}$, alginate, microspheres, amount of drug, aerosolization

\section{INTRODUCTION}

Metformin hydrochloride (metformin $\mathrm{HCl}$ ) is an antidiabetic drug that is specifically used for type 2 diabetes mellitus (DM) and belongs to the biguanide antidiabetic drugs. Metformin $\mathrm{HCl}$ has high solubility in water (Choudhury \& Mousumi, 2009). Metformin $\mathrm{HCl}$ has gastrointestinal side effects which include stomach discomfort, nausea, and vomiting. Metformin $\mathrm{HCl}$ also has short half-life, bioavailability of about $50-60 \%$ with no protein binding, large volume of distribution, and maximum accumulation in the small intestine (Zafar et al., 2014). These side effects need to be solved by creating models of microspheres which give sustained release effect (Choudhury \& Mousumi, 2009).

Microspheres are powder which is able to flow freely and ideally have a particle size of less than $200 \mu \mathrm{m}$ (Alagusurandam et al., 2009; Mujoriya, 2011). Its gradual release, sufficient to maintain the concentration of drug in the body, is one of the advantages of microsphere in the drug delivery system (Choudhury \& Mousumi, 2009). On the formation of microspheres of metformin $\mathrm{HCl}$ with ionotropic gelation method, some polymer and cross-linking solution is needed. A natural polymer that is commonly used is alginate.
Alginate is a natural polysaccharide which is generally found in the cell walls of brown algae species (Phaeophyceae). Sodium alginate is a natural biopolymer that has a biocompatible, biodegradable, and non-toxic properties and has a relatively low cost (Yang et al., 2007; Lee et al., 2011). Na alginate is composed of $(1 \rightarrow 4)$ - $\beta$-D-acid mannuronic $(M)$ units and $(1 \rightarrow 4)-\alpha$-L-guluronic acid $(\mathrm{G})$ units arranged in the form of homopolymer (a block of $\mathrm{MM}=$ mannuronic mannuronic or $\mathrm{GG}=$ guluronic guluronic) and heteropolymer (a block of $\mathrm{MG}=$ mannuronic guluronic and $\mathrm{GM}=$ guluronic mannuronic) (Lee et al., 2011).

Differences in the composition of mannuronic acid and guluronic acid lead to different physicochemical properties of alginate such as differences in stiffness of the yielded gel. The higher the ratio of guluronic, the harder and relatively more brittle the mass will be formed. Meanwhile, the higher the ratio of mannuronic, softer and more deformed the gel mass that is yielded (Erdinc, 2007). In this study, the type of $\mathrm{Na}$ alginate used is the one that has a higher guluronic ratio than mannuronic. The addition of $\mathrm{Ca}^{2+}$ ions or other divalent cations will form gelation through specific ionic bond and can cause a conformational change in the structure of the sodium alginate (Martin, 2002). $\mathrm{Ca}^{2+}$ ion is a divalent cation most commonly 
used than others (Kuo et al., 2001). Calcium chloride $\left(\mathrm{CaCl}_{2}\right)$ can be used as cross-linker in the formation of microspheres with alginate polymer. Levels of $\mathrm{Ca}^{2+}$ determine the density of the gel formed (Goundanavar et al., 2010).

The amount of drug affected physical characteristics of microspheres in increasing drug loading and entrapment efficiency. The method used in this study was ionotropic gelation (polyelectrolyte complexation). This method can produce spherical metformin-Ca alginate microspheres with smooth surfaces and size of 47.11 $\pm 16.5 \mu \mathrm{m}$ (Balasubramaniam et al., 2007). An advantage of the ionotropic gelation by aerosolization technique in this study is that all polyelectrolyte used is water-soluble therefore active agent can be encapsulated without use of organic solvents or high temperatures that can damage the active agent. In addition, this method is a simple, fast, cost-effective, and can produce small particle sizes of $<10 \mu \mathrm{m}$ (Hariyadi, 2014).

The drying technique was aimed at maintaining the stability of active agent and microspheres. Drying using the technique of freeze drying was deemed most appropriate to anticipate the instability. In the freeze drying, lyoprotectant needs to be added, namely maltodextrin that has the ability to maintain the stability of microspheres at higher temperatures compared to the others (Laura et al., 2010). Factors that may affect the characteristics of the microspheres produced are the amount of polymer, the number of crosslinker, and the amount of drug used.
This study was conducted to determine the effect of the amount of drug substance to the characteristics of metformin-Ca alginate microspheres with varying amounts of drug $(0.5 \mathrm{~g}-2 \mathrm{~g}), 2 \mathrm{~g}$ of polymer, and $2.5 \mathrm{~g}$ of crosslinker, using the ionotropic gelation with aerosolization technique.

\section{MATERIAL AND METHODS \\ Materials}

Metformin $\mathrm{HCl}$ (Combiphar); sodium alginate (Sigma-Aldrich); $\quad \mathrm{CaCl}_{2} \quad$ (Solvay Chemicals International); maltodextrin (PT BrataChem); sodium Citrate (Weifang Ensign Industry Co. Ltd) all in pharmaceutical grade; Distilled water.

\section{Methods}

\section{Microspheres formulation}

Sodium alginate (according to the formula in Table 1) was dissolved in $100 \mathrm{~mL}$ of aquademineralisata. Metformin $\mathrm{HCl}$ was dispersed into the alginate solution according to the formula and stirred until homogeneous. The resulting metforminalginate solution was sprayed using aerosol spray with a hole size of $35 \mu \mathrm{m}$, a constant pressure of $40 \mathrm{psi}$, and a spraying distance of $8 \mathrm{~cm}$ into $100 \mathrm{~mL}$ of $\mathrm{CaCl}_{2}$ and was stirred constantly for 30 minutes at the speed of $1000 \mathrm{rpm}$. Microspheres that are formed in centrifuges at a speed of $2500 \mathrm{rpm}$ for 6 minutes were then washed with distilled water 2 - 3 times. The microspheres that have been washed were dispersed in a $5 \%$ maltodextrin solution and dried using freeze drying at $-80^{\circ} \mathrm{C}$ for 29 hours.

Table 1. Formulas of metformin $\mathrm{HCl}$-alginate microspheres

\begin{tabular}{cccccc}
\hline Materials & Function & F1 & F2 & F3 & F4 \\
\hline Metformin $\mathrm{HCl}$ & Antidiabetic drug & $0.5 \mathrm{~g}$ & $1 \mathrm{~g}$ & $1.5 \mathrm{~g}$ & $2 \mathrm{~g}$ \\
Na Alginate & Polymer & $2 \mathrm{~g}$ & $2 \mathrm{~g}$ & $2 \mathrm{~g}$ & $2 \mathrm{~g}$ \\
$\mathrm{CaCl}_{2}$ & Crosslinker & $2.5 \mathrm{~g}$ & $2.5 \mathrm{~g}$ & $2.5 \mathrm{~g}$ & $2.5 \mathrm{~g}$ \\
Maltodextrin & Lyoprotectant & $5 \%$ & $5 \%$ & $5 \%$ & $5 \%$ \\
\hline
\end{tabular}

\section{Evaluation of metformin $\mathrm{HCl}$-alginate microspheres}

Following after production, metformin $\mathrm{HCl}-$ alginate microspheres were evaluated in terms of loadings, entrapment efficiency, yield, size and morphology.

The determination of metformin $\mathrm{HCl}$ content in microspheres

A standard curve of metformin $\mathrm{HCl}$ in a solution of $0.5 \mathrm{M} \mathrm{Na}$ Citrate $\mathrm{pH} 8.5$ at a concentration of 4 - 15 ppm was produced. Then, $150 \mathrm{mg}$ of microspheres were dispersed in $50 \mathrm{~mL}$ of $0.5 \mathrm{M} \mathrm{Na}$ Citrate $\mathrm{pH} 8.5$, and the mixture were stirred using magnetic stirrer at $1000 \mathrm{rpm}$ for 7 hours. Crosslinling time of microspheres was 30 minutes. The solution was then observed by a spectrophotometer at $\lambda 239 \mathrm{~nm}$ as the maximum wavelength. The metformin $\mathrm{HCl}$ concentration was determined.

\section{Characteristics of metformin $\mathrm{HCl}-\mathrm{Ca}$ alginate microspheres \\ Particle size distribution}

Measurement of 300 particles was conducted. The smallest and largest sizes from all samples were grouped and then divided into several intervals and class. The average diameter value was determined and a particle size distribution curve was created. 
Examination of the shape and surface of microspheres

The examination of the shape and surface of the wet metformin $\mathrm{HCl}$-alginate microspheres produced was done by using an optical microscope, the appearance was taken using a camera, and an observation of freeze dried microspheres using Scanning Electron Microscope (SEM) was conducted. SEM was performed by placing microparticles on the handle of preparation with some adhesive containing grains of metal, such as Pt metal. Gold on the Chamber was evaporated so that the gold steam coated the entire surface of the microparticles. The surface of the goldcoated microparticles was observed by the SEM.

\section{Examination of spectra infrared}

The spectroscopy test was performed to determine the drug-polymer interaction during the microencapsulation process. The infrared spectroscopy method was performed using $\mathrm{KBr}$ pellets in which samples of each formula were crushed and then weighed for as much as $2 \mathrm{mg}$. Some pro-spectroscopy $\mathrm{KBr}$ powder that has been dried for as much as $300 \mathrm{mg}$ was added. The mixture was crushed in a mortar until homogenous. Once homogeneous, the mixture was put in a $\mathrm{KBr}$ disc maker and pressed using a hydraulic press to obtain a transparent disc. The disc was placed in the sample holder and was recorded. Samples were observed at a wavelength of $4000-400 \mathrm{~cm}^{-1}$. The results of the examination of the microspheres' infrared spectrums were then compared with the infrared spectrum of the microspheres without drug ingredients.

Determination of loadings, entrapment efficiency and yield

The drug loadings in the microspheres was determined by breaking the metformin microspheres that has been formed with $50 \mathrm{~mL}$ of sodium citrate for 7 hours. From the standard curve and the absorbance of the drug in the microspheres, calculations of entrapment efficiency, the loadings of metformin $\mathrm{HCl}$, and yield can be performed as equation 1 and 2 (Balasubramaniam et al., 2007).

$$
\begin{aligned}
& \text { Entrapment Efficiency }=\frac{\text { metformin } \mathrm{HCl} \text { content measured }}{\text { theoretical content of metformin } \mathrm{HCl}} \times 100 \% \ldots \ldots \ldots \text { (1) } \\
& \text { Drug Loading }=\frac{\text { The total weight of metformin } \mathrm{HCl}}{\text { weight of microspheres }} \times 100 \% \ldots \ldots \ldots \ldots \ldots \ldots \text { (2) }
\end{aligned}
$$

From data of each inspection, the percentages metformin $\mathrm{HCl}$ loadings in the microspheres, the yield of microspheres, as well as drug entrapment efficiencies were obtained. These were compared to the respective formulas. The data analysis was performed using SPSS 23 statistical program with the One-Way ANOVA method.

\section{RESULTS AND DISCUSSION}

The observation of spectra F1-F4 showed the interaction between the drug, polymer, and the crosslinking solution $\mathrm{CaCl}_{2} \quad$ (Figure 1). Such interactions were marked by shifting wave numbers, the loss of guluronic fingerprint absorption, and one absorption of the carboxylate salt group $\left(1614 \mathrm{~cm}^{-1}\right)$ from $\mathrm{Na}$ alginate due to a crosslinking reaction with $\mathrm{CaCl}_{2}$.

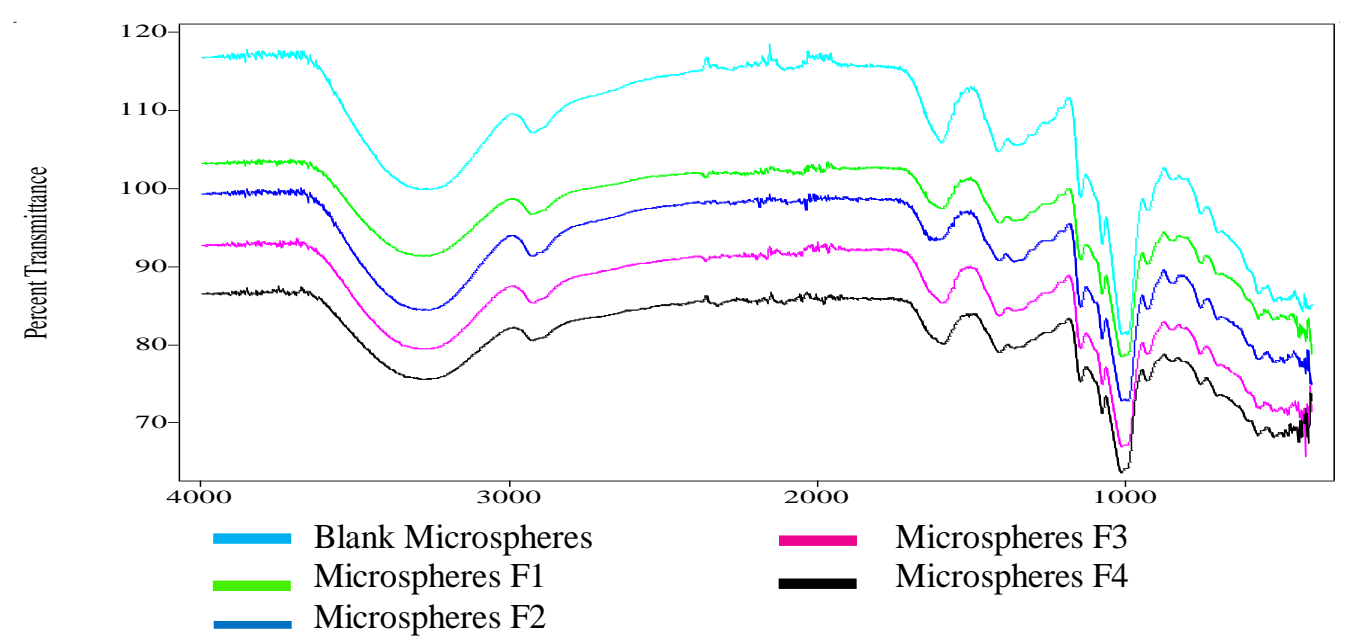

Figure 1. The overlay result of IR spectrum examination of metformin-alginate microspheres with the ratio of metformin amount 
Particle sizes of the all formulas showed that the particle sizes of the four formulas (Figure 2). All formulas resulted in bigger particle size than blank microspheres $(0.8-1 \mu \mathrm{m})$. The observations also showed an increase in particle size with the increasing amount of metformin $\mathrm{HCl}$ drug from $\mathrm{F} 1$ to $\mathrm{F} 4$, which is from $0.5 \mathrm{~g}$ to $2 \mathrm{~g}$ (Figure 3).

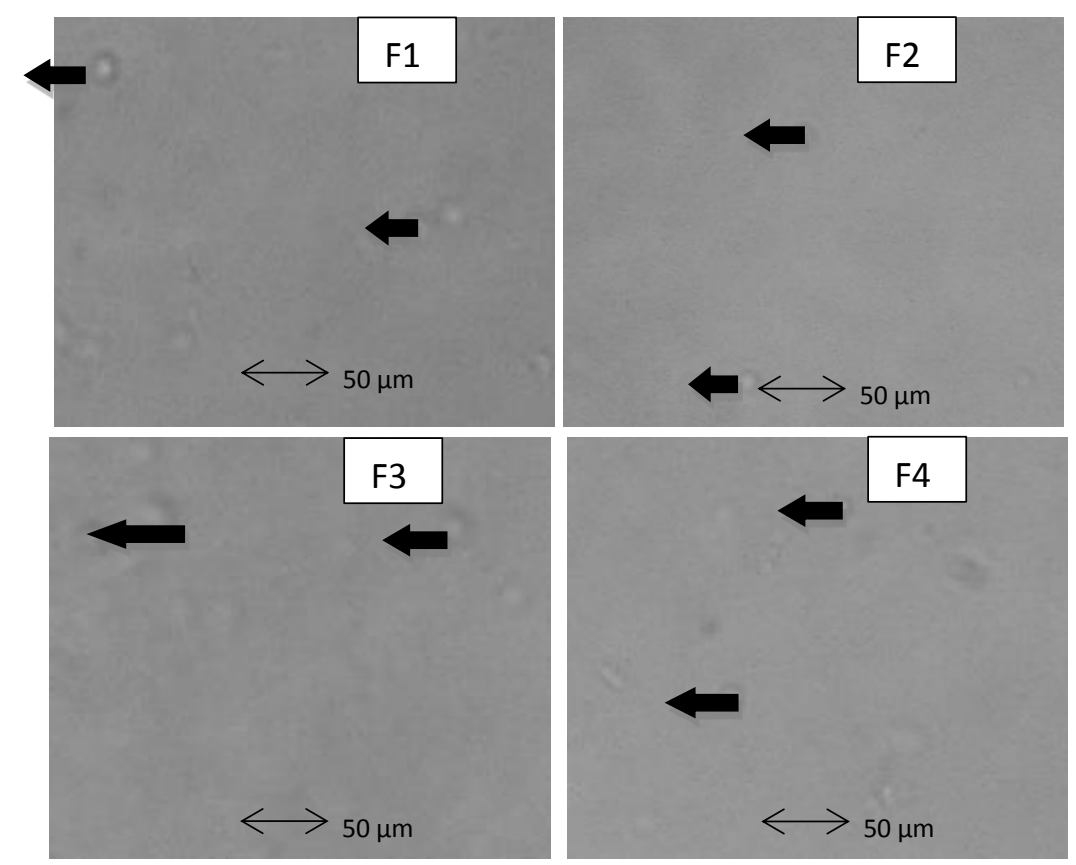

Figure 2. Morphology of metformin $\mathrm{HCl}$-Alginate microspheres in formulas F1, F2, F3, and F4 using a 400x magnification optical microscope

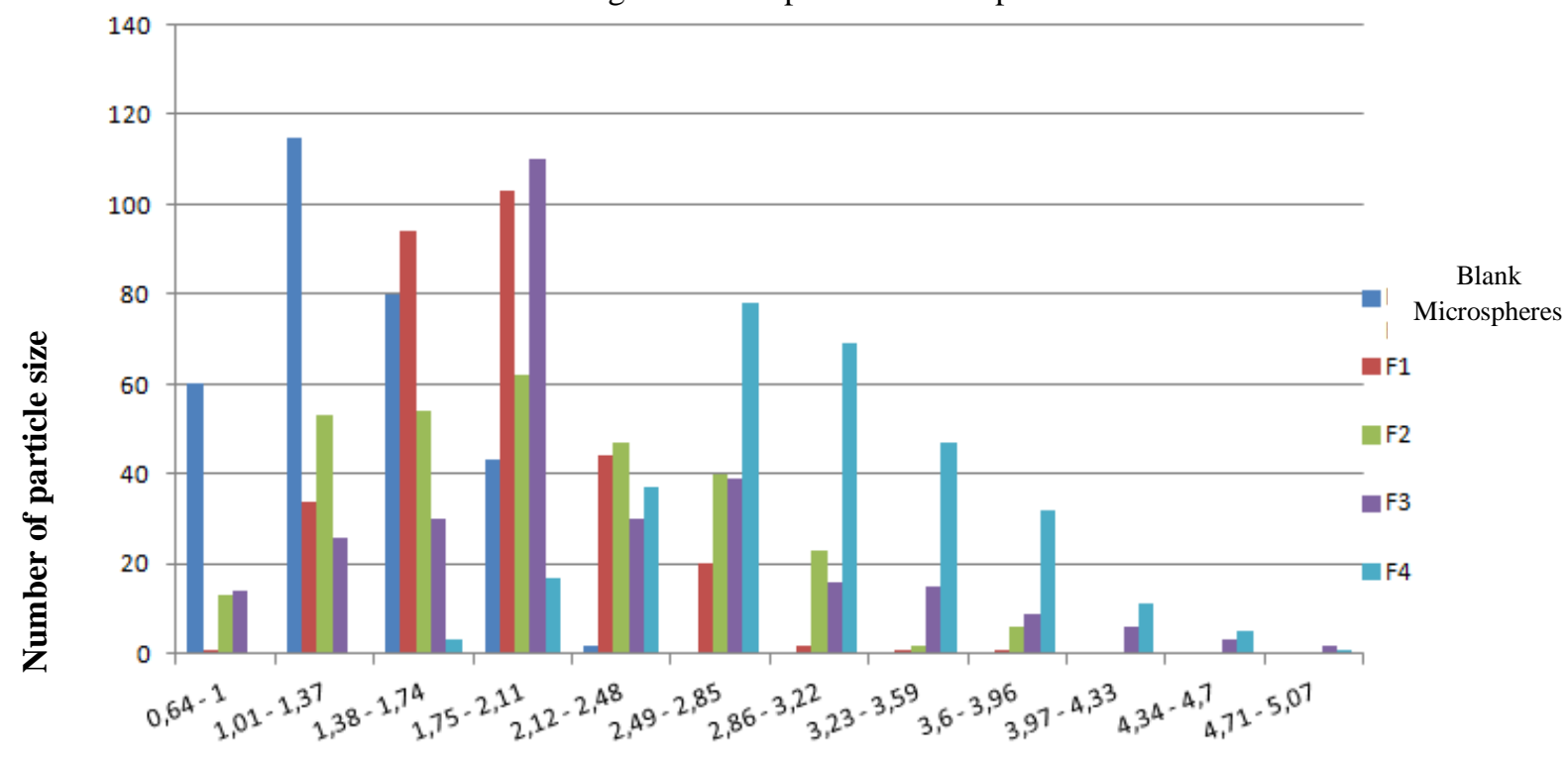

Particle size Interval

Figure 3. The particle sizes of microspheres

The results of the examination of microspheres shapes and surfaces using a Scanning Electron Microscope (SEM) showed that the microspheres of F1 to F4 were spherical and smooth in terms of surface (Figure 4). This was due to the addition of maltodextrin to make microspheres spherical, smooth, and flat in surface by covering cavities or pores on the surface of the microspheres that increased in number and size during the process of freeze-drying through the formation of hydrogen bonds with polar groups on the surface of the microspheres (Abdelwahed et al., 2006). 

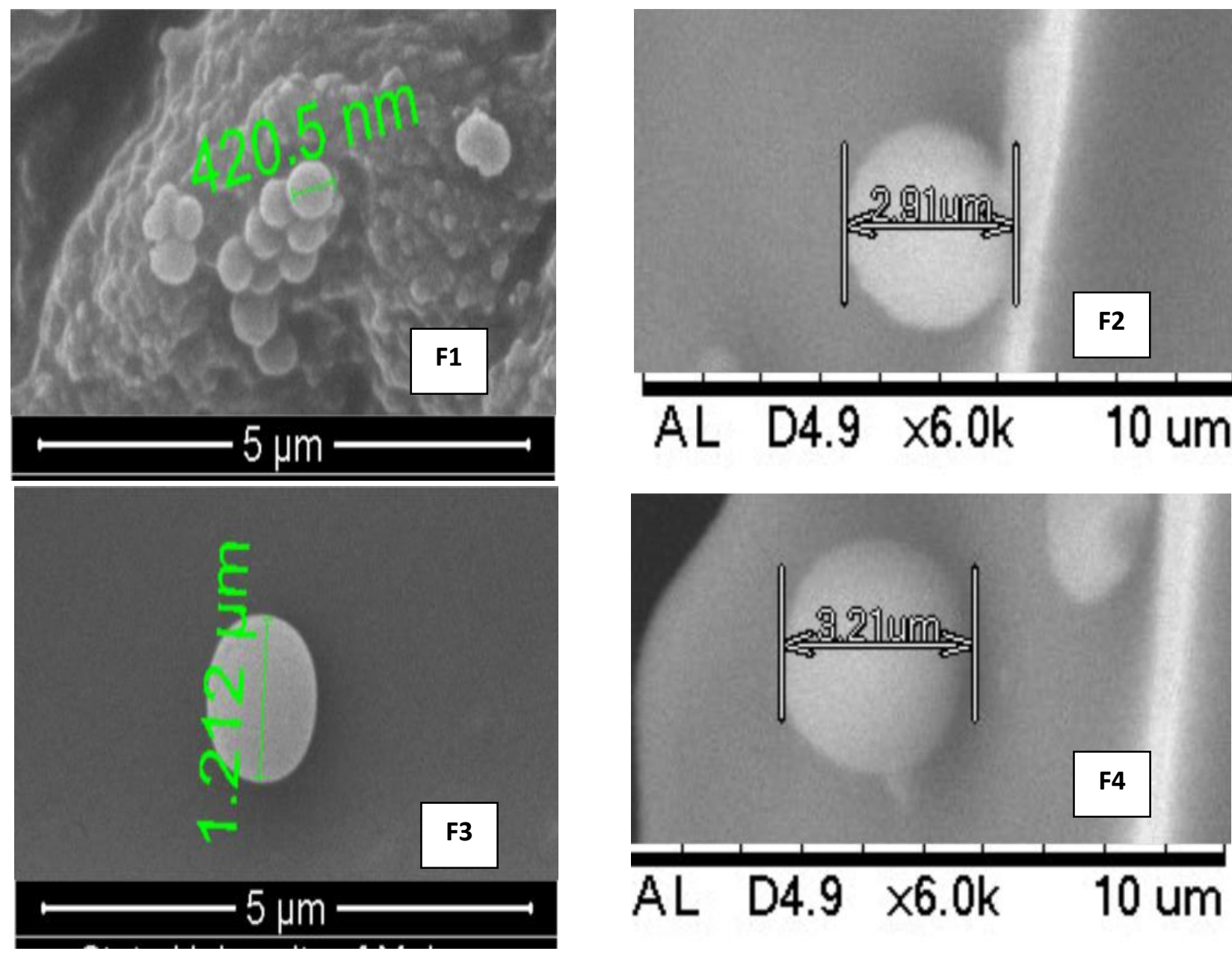

Figure 4. Morphology of $\mathrm{HCl}$ metformin-Alginate microspheres of F1, F2, F3, and F4 using Scanning Electron Microscope (SEM)

\section{Entrapment efficiency, yield and drug loading}

The results of the drug content, entrapment efficiency and yield of metformin $\mathrm{HCl}$ in microspheres can be seen in Table 2. The low drug loadings of metformin $\mathrm{HCl}$ in microspheres obtained was partly because metformin $\mathrm{HCl}$ was a drug with a low molecular weight and a high solubility in water for metformin $\mathrm{HCl}$ was easily detached from the microspheres during the manufacturing process and because the capacity of the microspheres was not able to adsorb the drug ingredients that are too high with amount of 2 grams of alginate (Rastogi et al., 2007). Statistical analysis showed that the varying amount of metformin $\mathrm{HCl}$ gave a significant difference, a sig value of $0,001<0.05$ for the comparison between $\mathrm{F} 1$ : $\mathrm{F} 2 ; 0.000<0.05$ for the comparison between F1: F3; $0.000<0.05$ for comparison F1: F4; $0.006<0.05$ for the comparison between $\mathrm{F} 2$ : F3; and $0.000<0.05$ for the comparison between $\mathrm{F} 2$ : $\mathrm{F} 4$ to metformin $\mathrm{HCl}$ loadings in the microspheres.

Table 2. Drug loadings, entrapment efficiency, and yield of microspheres

\begin{tabular}{cccc}
\hline Formula & $\begin{array}{c}\text { Drug Loadings of } \\
\text { metformin }(\%)\end{array}$ & $\begin{array}{c}\text { Entrapment efficiency } \\
(\%)\end{array}$ & Yield (\%) \\
\hline F1 & $5.09 \pm 0.19$ & $48.35 \pm 1.11$ & $80.92 \pm 1.78$ \\
F2 & $9.61 \pm 0.94$ & $41.99 \pm 1.71$ & $74.12 \pm 2.24$ \\
F3 & $13.11 \pm 1.39$ & $38.67 \pm 2.96$ & $68.27 \pm 6.78$ \\
F4 & $15.09 \pm 0.49$ & $30.53 \pm 5.37$ & $59.11 \pm 9.77$ \\
\hline
\end{tabular}

The entrapment efficiency of the microspheres decreased by increasing in the number of metformin $\mathrm{HCl}$ (Table 2). The cause of the decline was because the entrapment efficiency of microspheres has a maximum capacity to adsorb drug substances at a certain alginate concentration since to produce the optimal amount of entrapped drug in the microspheres, the amount of polymer and crosslinker should be 
appropriate (Patil et al., 2010). This was evidenced by the percentage of entrapment efficiency of metformin $\mathrm{HCl}$ in $\mathrm{F} 1$ that was greater than in F4. Statistical analysis showed that the influence of the amount of metformin $\mathrm{HCl}$ gives a significant difference with the obtained sig value of $0.026<0.05$ for the comparison between F1:F3; $0.001<0.05$ for comparison F1:F4; and $0.011<0.05$ for the comparison between F2:F4 against entrapment efficiency of metformin $\mathrm{HCl}$ in microspheres since the value was less than 0.05 .

The increasing number of metformin $\mathrm{HCl}$ decreased the yield value (Table 2). This was because the entrapment of microspheres has an adsorption capacity therefore some drug ingredients were not binding and did not get into joint microspheres and were washed during the washing of microspheres (Rastogi et al., 2007). This was given that the nature of metformin $\mathrm{HCl}$ itself that is readily soluble in water. Statistical analysis showed that the influence of the amount of metformin $\mathrm{HCl}$ gave a significant difference with the obtainment of sig value of $0.026<0.05$ for the comparison between F1:F3; $0.001<0.05$ for comparison F1:F4; and $0.011<0.05$ for the comparison between $\mathrm{F} 2: \mathrm{F} 4$ against entrapment efficiency of metfomin $\mathrm{HCl}$ in microspheres since the value was less than 0.05 .

\section{CONCLUSION}

The formulation of metformin $\mathrm{HCl}-\mathrm{Ca}$ alginate microspheres using the aerosolization technique was successfully produced microspheres with a size of $<10 \mu \mathrm{m}$, that are spherical and smooth. The increase amount of metformin $\mathrm{HCl}$ increased the drug loadings of metformin $\mathrm{HCl}$-alginate microspheres and lowered the entrapment efficiency and yield. This results suggested the potential use for oral delivery system.

\section{ACKNOWLEDGMENT}

The author would like to thank the Faculty of Pharmacy, Airlangga University for all facilities to support this research.

\section{REFERENCES}

Abdelwahed, W., Degobert, G., Stainmesse, S. \& Fessi, H. (2006). Freeze-drying of Nanoparticles: Formulation, Process and Storage Considerations. Advanced Drug Delivery Reviews; 58; 16881713.

Alagusurandam, M., Madhu, S. C. C., Umashankari, K., Attuluri, V. B., Lavanya, C. \& Ramkanth, S. (2009). Microspheres as a Novel Drug Delivery
System. International Journal of ChemTech Research; 1; 526-534.

Balasubramaniam, J., Vinay, U., Rao, M., Vasudha, J. B. \& Rajinikanth, P. S. (2007). Sodium Alginate Microspheres of $\mathrm{HCl}$ Metformin: Formulation and In Vitro Evaluation. Current Drug Delivery; 4; 249-256.

Choudhury, P. K. \& Mousumi, K. (2009). Controlled Release Metformin Hydrochloride Hicrospheres of Ethyl Cellulose Prepared by Different Methods and Study on the Polymer Affected Parameters. Journal of Microencapsulation; 26; 46-53.

Erdinc, B. I. (2007). Micro/Nanoencapsulation of Proteins Whitin Alginate/Chitosan Matrix by Spray Drying. Thesis; Queen's University, Brisbane.

Goundanavar, P. S., R. S., Bagali, C. S. \& Patil, S. M. (2010). Design and Characterization of Diclofenac Sodium Microbeads by Ionotropic Gelation Technique. International Journal of Pharma and Bio Sciences; 1; 1-10.

Hariyadi, D. M., Tutiek, P. \& Rahma, N. N. (2014). Effect of Lactose and Maltodectrin on the Physical Characteristics of Ovalbumin-loaded Alginate Microspheres Produced by Aerosolization. International Journal of Life Sciences Biotechnology and Pharma Research; 5; 26-29.

Kuo, C. K. \& Peter, X. M. (2001). Ionically Crosslinked Alginate Hydrogels as Scaffolds for Tissue Engineering: Part 1. Structure, Gelation Rate and Mechanical Properties. Biomaterials; 22; 511-521.

Laura, T. R. F., Antonio, P. P. \& Mercedes, E. C. (2010). Inulin Like Lyoprotectant of Bovine Plasma Proteins Concentrated by Ultrafiltration. Food Research International; 43; 788-796.

Lee, K. Y. \& David, J. M. (2012). Alginate: Properties and Biomedical Applications. Progress in Polymer Science; 37; 106-126.

Martin, M. (2002). Surfactans and Polymers in Drug Delivery. New York: Marcel Dekker, Inc.

Mujoriya, R. \& Bodla, R. B. (2011). Microsphere - An Overview. Journal of Biology, Agriculture and Healthcare; 1; 27-33.

Patil, J. S., Kamalapur, M. V., Marapur, S. C. \& Kadam, D. V. (2010). Ionotropic Gelation and Polyelectrolyte Complexation: The novel Thechniques to Design Hydrogel Particulate Sustained, Modulated Drug Delivery System. 
Digest Journal of Nanomaterials and Biostructures; 5; 241-248.

Rastogi, R., Sultana, Y., Aqil, M., Kumar, S., Chuttani, K. \& Mishar, A. K. (2007). Alginate Microspheres of Isoniazid for Oral Sustained Drug Delivery. International Journal of Pharmaceutics; 334; 71-77.

Yang, L., Bifang, Z., Liqum, W., Qiuyi, L. \& Li-Ming,

Z. (2007). Amphiphilic Cholesteryl Grafted
Sodium Alginate Derivative: Synthesis and Self Assembly in Aqueous Solution. Carbohydrate Polymers; 68; 218-225.

Zafar, A., Bhattacharyya, A., Bajpai, M., Yasir, M. \& Asif, M. (2014). Formulation and In Vitro Characterization of Floating Gel Beads of Metformin Hydrochloride._International Journal of Pharmacy and Pharmaceutical Sciences; 7; 2356-2362. 